\title{
Satellite Radar Observations of Small Eddies in the White, Barents and Kara Seas
}

\author{
O.A. Atadzhanova ${ }^{1,2, *}$, A.V. Zimin ${ }^{1,2}$, D.A. Romanenkov ${ }^{2}$, I.E. Kozlov ${ }^{2,3}$ \\ ${ }^{1}$ Saint-Petersburg Branch of the P.P. Shirshov Institute of Oceanology, Russian Academy of Sciences, \\ Saint-Petersburg, Russian Federation \\ *e-mail: oksana.atadzhanova@gmail.com \\ ${ }^{2}$ Russian State Hydrometeorological University, Saint-Petersburg, Russian Federation \\ ${ }^{3}$ Marine Hydrophysical Institute, Russian Academy of Sciences, Sevastopol, Russian Federation
}

\begin{abstract}
Analysis of space-time variability of small (submesoscale) eddies identified in satellite radar images during the warm season in the White (2009-2012), Barents and Kara (2007) Seas is presented. Determination of eddy locations, their diameters and vorticity type enabled to reveal the regions of regular eddy occurrence and assess their intraseasonal variability. In total, over 3500 eddy patterns were detected with 2970 cyclonic and 621 anticyclonic eddies. The peak of eddy activity in the Barents and White seas is observed in July, in the Kara Sea - in August. Despite a significant intraseasonal variability of eddy diameters, most eddies have diameters less than $6 \mathrm{~km}$. Mean values of eddy diameter range from $2.4 \mathrm{~km}$ for the Kara Sea to $4.7 \mathrm{~km}$ for the White Sea, with $3.6 \mathrm{~km}$ obtained for the Barents Sea. While cyclonic eddies are observed more frequently, anticyclonic eddies are typically larger in size. In the Barents Sea eddies are regularly observed near Svalbard and north to the Kola Peninsula; in the Kara Sea - between Novaya Zemlya and the Yamal Peninsula, and close to Uyedineniya and Sverdrup islands; in the White Sea - in the Dvina Bay, northward to the Solovetsky Islands and along the Tersky coast. In all the seas a significant part of the detected eddies is found near hydrological fronts of various origin.
\end{abstract}

Keywords: sub-mesoscale eddies, satellite radar images, statistics of vortex formation, the White Sea, the Barents Sea, the Kara Sea.

DOI: 10.22449/1573-160X-2017-2-75-83

(C) 2017, O.A. Atadzhanova, A.V. Zimin, D.A. Romanenkov², I.E. Kozlov

(C) 2017, Physical Oceanography

Introduction. Relative to the research of the formation and interaction regularities of various-scale hydrophysical fields and processes in the ocean, a large number of the recent works has been aimed at studying sub-mesoscale structures. Small eddies and local fronts were found to be of particular interest [1 -4$]$. These structures are associated with the most important scale in the ocean - the first baroclinic radius of deformation (or an internal Rossby radius) the breakdown of geostrophic and hydrostatic balances occurs at. As a result, transitional sub-mesoscale processes are characterized by sharp gradients of hydrological parameters and a short lifetime of the corresponding inhomogeneities. It makes it difficult to observe them by contact methods. In the present paper, by sub-mesoscale processes the eddies with diameters of 1 to $10 \mathrm{~km}$ are implied. High-resolution numerical models can reproduce such processes in limited areas. But at the same time they need new experimental information on sub-mesoscale structures for the development of adequate parametrizations of heat and substance fluxes transferred by mesoscale and sub-mesoscale motions in large-scale ocean models [5].

High-resolution satellite data gives the possibility to expand significantly our understanding of small-scale and sub-mesoscale structures and their dynamics [6 - 13]. A systematic analysis of such data for the Arctic seas has not been carried out down to here, except for the White Sea [13]. In addition, it is of interest to compare 
the features of the distribution of surface manifestations of eddy structures for the different in their morphometric and hydrological features in the Arctic seas.

The present work aims to analyze the spatial-temporal variability of the characteristics of sub-mesoscale eddies in the waters of the White, Barents and Kara Seas by their surface manifestations on satellite radar images (RI) during the warm (ice-free) period of the year.

Study area. Among the shelf Arctic seas, the Barents, White and Kara Seas are characterized by strong tidal currents, significant bottom irregularities and pronounced frontal zones. The waters of these seas are inhomogeneous and formed under the combined effect of circulation and energy exchange with the atmosphere. The water entry from other basins and the inhomogeneous topography create a very complex system of the surface (Fig. 1), intermediate and deep currents. The key role in this system play: the numerous branches of the Nordkapp Current and the cold waters of the Arctic Basin and the Kara Sea - for the Barents Sea; the water entry from the Barents Sea and the river runoff - for the White Sea; entry of the river waters, the relatively warm waters from the Barents Sea and cold Arctic waters from the north - for the Kara Sea [14].
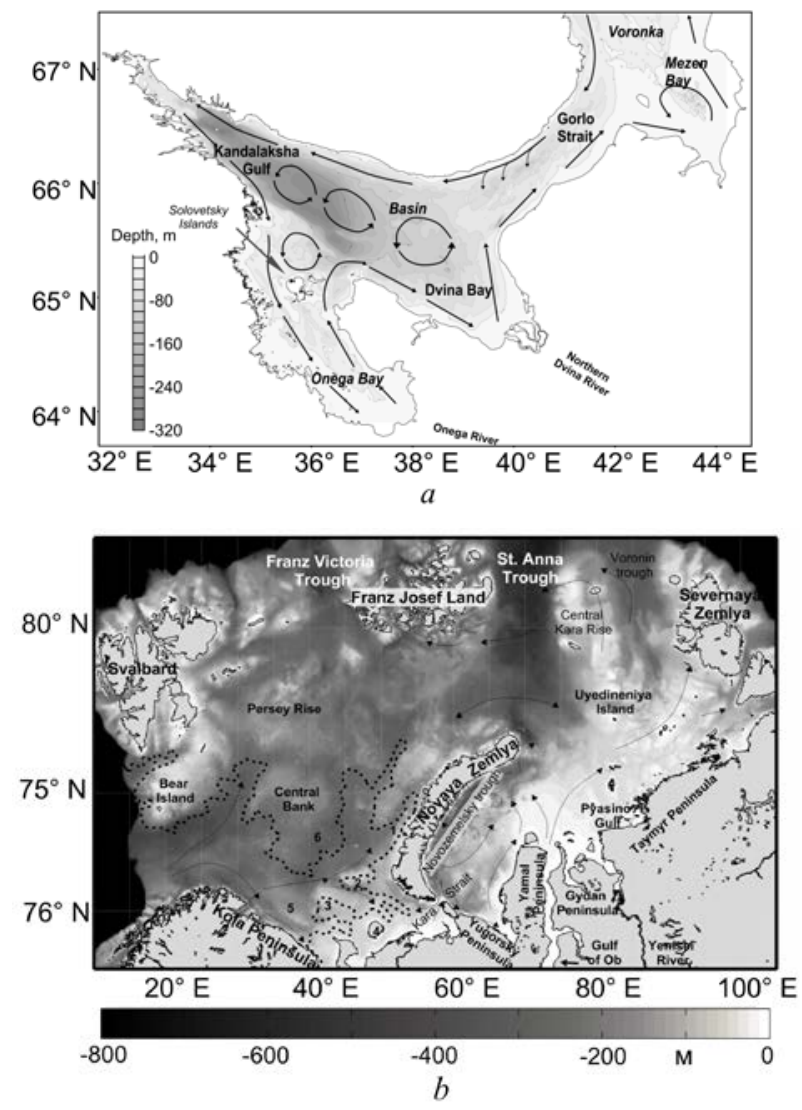

Fig. 1. Bathymetrical maps of the White $(a)$, Barents and Kara $(b)$ Seas. The arrows indicate climatic surface currents, the dotted line indicates the average climatic position of the polar front; 1 - the Matochkin Strait; 2 - Gusinaya Banka; 3 - Severnaya Kaninskaya Banka; 4 - Kolguyev Island; 5 Murmansk elevation; 6 - Central hollow [14] (see also p. 82) 
Data and methods. In the present paper $2312 C$-band Envisat ASAR radar images in WSM (400 $\times 400 \mathrm{~km}$ swath width, $150 \times 150 \mathrm{~m}$ spatial resolution) and $I M P(100 \times 100 \mathrm{~km}$ и $25 \times 25 \mathrm{~m}$ respectively) modes acquired during the ice-free period of 2007 - 2011 are used. 209 of the aforementioned images refer to the White Sea, 1203 - to the Barents Sea and 900 - to the Kara Sea. In addition, 12 images from Radarsat-1 in SGF (Path Image) mode with $25 \mathrm{~m}$ spatial resolution and Radarsat-2 in Fine Quad-Pol mode with $6 \mathrm{~m}$ spatial resolution for 2012 were used for the White Sea. The method of eddy identification in the RI and determination of their parameters (including the diameter of the eddy and its rotation sign) is presented in [13]. Further, based on the information obtained from the radar information, the basic statistical characteristics of the eddies were calculated and maps of the spatial distribution of their parameters were constructed.

Results and their discussion. Over 3.500 eddy structures were recorded from the satellite data analysis, of which 2.970 had a cyclonic $(\mathrm{Cn})$ type of rotation, 621 - the anticyclonic (Ac) one. Domination of the number of cyclonic eddies over the anticyclonic ones is characteristic for all the seas considered. Statistical parameters of the eddies are presented in the Table below.

In the smallest area of the White Sea, the least amount of eddy structures was detected, despite a longer period of observations. About $70 \%$ of the total number of eddies was recorded in June and July. As a rule, the observed eddies had a cyclonic type of rotation, while the anticyclonic eddies were always larger in size than the cyclonic ones.

In the Barents Sea having the largest area, the maximum number of vortex structures was found (see Tab.). It should be taken into consideration that this sea has the best coverage by satellite imagery and the smaller area of the ice cover during the warm period in comparison with the Kara Sea. The largest number of vortices is observed in July, the smallest (10 \% of the total number) - in October. In June and August their number is approximately the same. The average size of all the vortices varied between 2.3 and $4.3 \mathrm{~km}$, while, like in the White Sea, the anticyclonic vortices were larger in diameter, and the largest vortices were encountered mainly in July and August.

Almost 2 times less vortex structures were found in the Kara Sea than in the Barents Sea (see Tab.), but with a more significant predominance of cyclonic vortices. Almost $40 \%$ of all vortices were observed in August, the least (15\%) - in September. Vortices in the Kara Sea are smaller in size than in the rest of the seas, with an average diameter of $2.4 \mathrm{~km}$ within the entire period. The average value of the diameter of anticyclonic vortices is also greater than that of the cyclonic ones.

Fig. 2 shows that the vortex structures are quite common and occur practically throughout the entire water area of each of the seas considered. In the Barents Sea, they were rarely recorded in the central part, most often - to the south-east of Bear Island, near the eastern shore of Western Spitsbergen, to the west of Franz Josef Land and Novaya Zemlya and also near the Matochkin Strait. The number of vortices in these areas was more than 18 per grid square (the grid square on the map has an average area of $2.500 \mathrm{~km}^{2}$ ), near Spitsbergen and to the north of the Kola Peninsula (asterisks in Fig. 2, $b$ ) - 37 per grid square. 
Parameters of Eddies in the White, Barents and Kara Seas according to Satellite Radar Measurements

\begin{tabular}{|c|c|c|c|c|c|c|}
\hline \multirow[t]{2}{*}{ Month } & \multicolumn{3}{|c|}{ Number of eddies } & \multicolumn{2}{|c|}{$\begin{array}{l}\text { Average (min - max) } \\
\text { diameter, km }\end{array}$} & \multirow{2}{*}{\begin{tabular}{|c|c}
$\begin{array}{c}\text { Average } \\
\text { liameter, km }\end{array}$ \\
$A c+C n$
\end{tabular}} \\
\hline & Ac & $\mathrm{Cn}$ & $A c+C n$ & Ac & $\mathrm{Cn}$ & \\
\hline \multicolumn{7}{|c|}{ The White Sea, 2009 - 2012} \\
\hline May & - & 1 & 1 & - & 2.2 & 2.2 \\
\hline June & 9 & 41 & 50 & $8(2.9-13.2)$ & $4.5(1.4-9.3)$ & 5.1 \\
\hline July & 18 & 38 & 56 & $5.1(0.9-12.1)$ & $5.6(2.1-10.6)$ & 5.4 \\
\hline August & 7 & 24 & 31 & $3.5(1.2-5.5)$ & $3.3(1.1-7)$ & 3.4 \\
\hline September & 4 & 20 & 24 & $5.8(1.2-12.5)$ & $3.6(1.5-9.6)$ & 4.0 \\
\hline Total & 38 & 124 & 162 & $5.6(0.9-13.2)$ & $4.4(1.1-10.6)$ & 4.7 \\
\hline \multicolumn{7}{|c|}{ The Barents Sea, 2007} \\
\hline June & 103 & 390 & 493 & $4.7(0.3-17.1)$ & $4(0.3-15.6)$ & 4.2 \\
\hline July & 139 & 498 & 637 & $6(0.2-21)$ & $3.8(0.2-25)$ & 4.3 \\
\hline August & 156 & 366 & 522 & $3.5(1-18.3)$ & $3.7(0.7-20.4)$ & 3.6 \\
\hline September & 83 & 279 & 362 & $2.4(0.5-12.1)$ & $2.2(0.2-15.9)$ & 2.2 \\
\hline October & 25 & 148 & 173 & $2.9(0.5-10.6)$ & $2.2(0.4-9.8)$ & 2.3 \\
\hline Total & 506 & 1681 & 2187 & $4.2(0.2-21)$ & $3.4(0.2-25)$ & 3.6 \\
\hline \multicolumn{7}{|c|}{ The Kara Sea, 2007} \\
\hline July & 17 & 359 & 376 & $2.9(1.1-6.8)$ & $2.4(0.9-6.2)$ & 2.5 \\
\hline August & 46 & 434 & 480 & $2.9(1.6-8.3)$ & $2.6(0.8-13.6)$ & 2.7 \\
\hline September & 12 & 176 & 188 & $3.6(1.7-5.9)$ & $3(1.1-14.4)$ & 3 \\
\hline October & 2 & 196 & 198 & $1.6(1.2-2)$ & $1.2(0.4-7.2)$ & 1.2 \\
\hline Total & 77 & 1165 & 1242 & $2.8(1.1-8.3)$ & $2.3(0.8-14.4)$ & 2.4 \\
\hline
\end{tabular}

In the Kara Sea, eddies were not practically found in the deep-water part of the St. Anne Trench and Novozemelskaya trough, as well as in the northern part of the central basin. They were most often recorded in the area of Uedineniya and Sverdrup (the Pyasino Gulf) Islands, as well as near the western coast of the Yamal Peninsula and to the south of Cape Zhelaniya. The amount of eddies in these areas was more than 18 per grid square, the maximum one ( 27 vortices per grid square) was observed to the south of the northern tip of Novaya Zemlya (the triangle in Fig. 2, $b$ ).

In the White Sea (Fig. 2, a), the eddy structures were most often observed near the Tersky coast, to the north of the Solovetsky Islands and in the Dvina Gulf, rarely in the central parts of the Gorlo Strait and the Basin, most seldom - in the Gorlo. In the greatest eddy activity zones $4-6$ eddies per grid square (equal to $\sim 144 \mathrm{~km}^{2}$ ) were observed. 

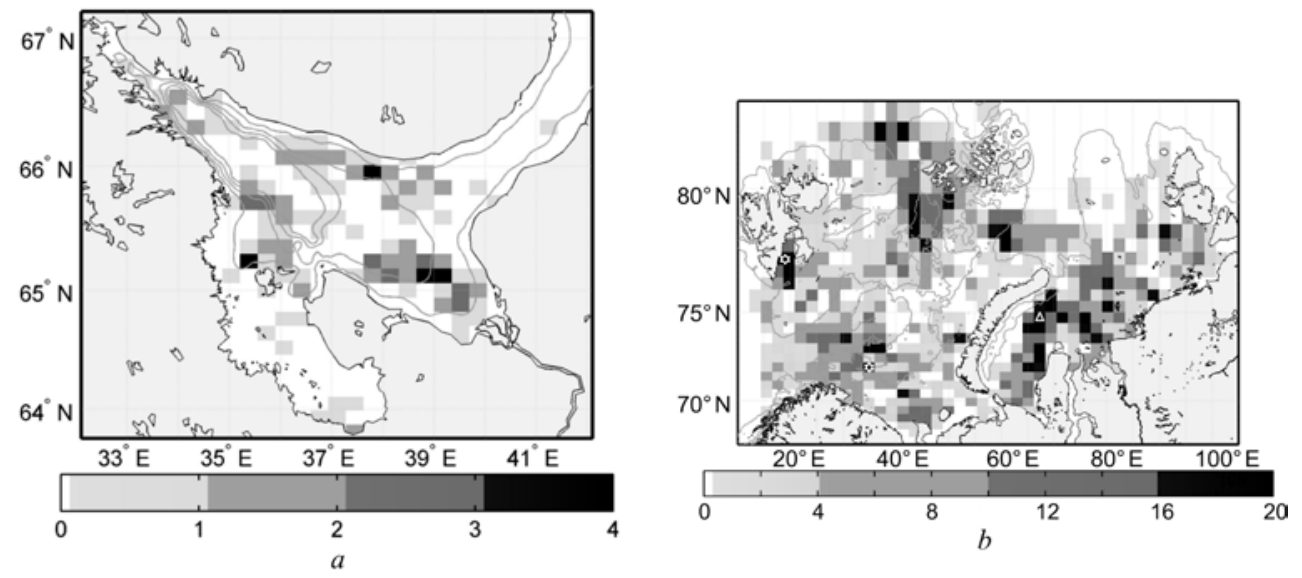

Fig. 2. Spatial distribution of the number of vortex structures per grid square for the White $(a)$, Barents and Kara $(b)$ Seas. Isolines of the depths are drawn through $50 \mathrm{~m}(a)$ and $250 \mathrm{~m}(b)$. The square of the grid in the White Sea is $144 \mathrm{~km}^{2}$, in the Barents and Kara Sea $-2.500 \mathrm{~km}^{2}$

Comparing the eddy size distribution (Fig.3), the largest diameters (over $8 \mathrm{~km}$ ) should be noted. They were recorded mainly in the western and central parts of the Barents Sea, where, according to climatic data, a warm Atlantic water inflow is observed. In the eastern part of the Barents Sea and in the Kara Sea, the eddies had a diameter of up to $5 \mathrm{~km}$. In the White Sea, under the influence of considerable tidal dynamics, the large eddies are formed practically over the entire basin [13].
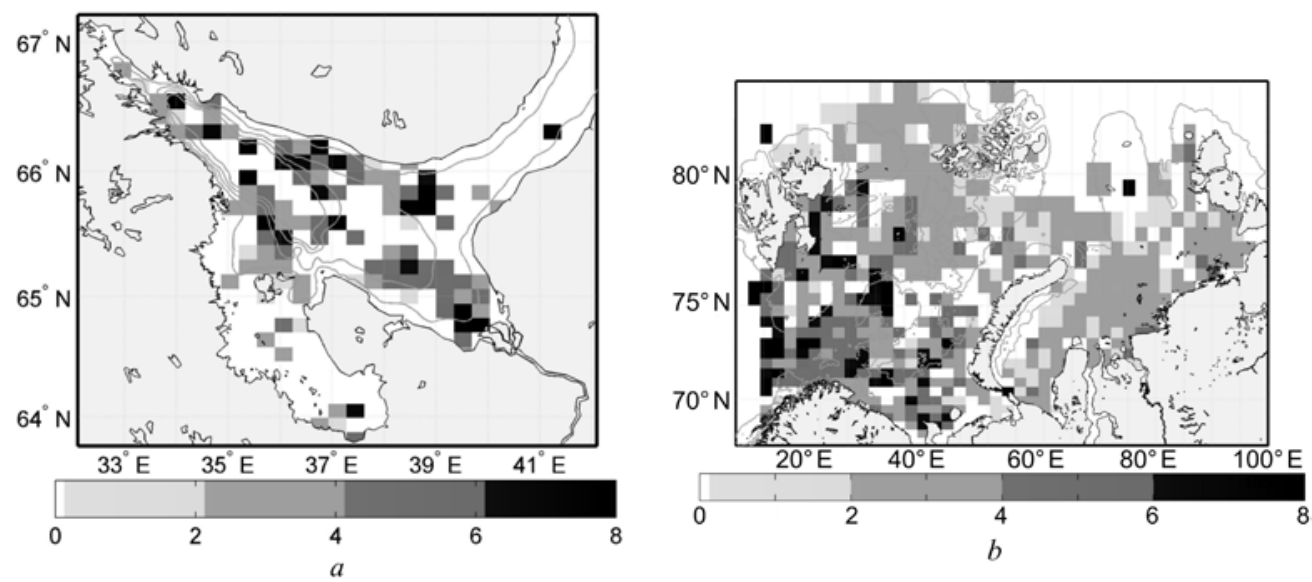

Fig. 3. Spatial distribution of diameters of eddy structures in the water area of the White $(a)$, Barents and Kara $(b)$ Seas. The symbols are the same as in Fig. 2

The sizes of the observed vortex formations were compared with the estimates of the baroclinic Rossby radius in the studied seas, obtained from the data of the ESIMO climatic atlas (http://www.esimo.ru/atlas/). The calculation results for July - August showed that the minimum and maximum values of the radius for the White Sea were 1.3 and $8 \mathrm{~km}$, for the Barents Sea -0.2 and $9.5 \mathrm{~km}$, for the Kara Sea -0.2 and $6 \mathrm{~km}$. Its mean values are 4.3; 4.9 and $3 \mathrm{~km}$ for the White, Barents and Kara Seas, respectively, which is not rejected by the estimates of the Rossby PHYSICAL OCEANOGRAPHY NO. 2 (2017) 
radius obtained for the warm season on the basis of another database [15]. In addition, according to data from long-term in situ measurements in selected areas of the White Sea, the seasonal and interannual variability of the Rossby radius also ranged from 1 to $8 \mathrm{~km}$ with the mean values close to climatic estimates [13].

In accordance with the Table and Fig. 3 the size of the eddies in the White Sea varied from 1 to $13 \mathrm{~km}$ with a mean value of $4.7 \mathrm{~km}$, in the Barents Sea - from 0.2 to $25 \mathrm{~km}$ with a mean value of $3.6 \mathrm{~km}$, in the Kara Sea - from 0.4 to $14.4 \mathrm{~km}$ with a mean value of $2.4 \mathrm{~km}$. Despite the considerable seasonal variability of the eddy dimensions, the maximum repeatability is observed for the eddies with a diameter value close to the above estimates of the mean Rossby radius (Fig. 4). Some of the eddies have diameters less than $6 \mathrm{~km}$, which corresponds to the maximum value of the Rossby radius in the Kara Sea. This value can be considered a characteristic upper limit for sub-mesoscale eddies in the studied Arctic seas.

The above information on the spatiotemporal variability of the amount and dimensions of the eddies in the water area of the three Arctic seas allows to make a few remarks on possible mechanisms of vortex formation.

The paper [16] shows that eddy structures are formed under the influence of the dynamics and/or instability of hydrological fronts in the White Sea. In the Dvina and Onega Bays, the active dynamics of the runoff fronts, caused by the river runoff maximum in June and July, determines the more frequent eddy registration from space in these months. In the areas of tidal front existence, for example, in the Gorlo Strait and in the vicinity of the Solovetsky Islands, eddies are less frequently observed and do not have a pronounced seasonal cycle. The main cause of vortex formation in these areas was frontal instability (meandering). Another mechanism associated with topographic effects in the interaction of the tidal flow with the irregular bottom topography was favorable for the eddy generation in the region to the north of the Solovetsky Islands and in the Basin along the Tersky coast (Fig. 2, a).

In the Barents Sea, the Polar frontal zone, where the modified waters of the Barents Sea are divided into the Arctic and Atlantic waters (Fig. 1), plays an important role in the structuring of increased eddy activity areas. Intensification of the Atlantic waters inflow and seasonal ice melting in spring and early summer causes aggravation and activity of the southern (between the Barents Sea and the Atlantic waters) and the northern (between the Arctic and Barents Sea waters) fronts. Apparently, this process seems to explain the presence of the identified zones of regular eddy observation to the north of the Kola Peninsula, to the southwest and southeast of Franz Josef Land (Fig. 2). The mechanism of topographic eddy formation, including the areas of strong tidal currents, also needs to be taken into consideration. In particular, this mechanism should be manifested at the shelf edge to the northwest of Franz Josef Land, at the entrance to the White Sea, and over the banks and troughs in the central part of the Barents Sea.

Thin halocline and saline front formed by the $\mathrm{Ob}$ and Yenisei runoff determine the leading role in the eddy activity increase in the Kara Sea. There is intensification in the river runoff in July and August. It affects the southern and eastern parts of the Kara Sea, the formation of modified waters of the Kara Sea and the strengthening of the frontal zone with summer Barents Sea and Arctic waters. These are those very areas where the largest amount of eddies has been recorded in summer months (Fig. 2 and Tab.). 

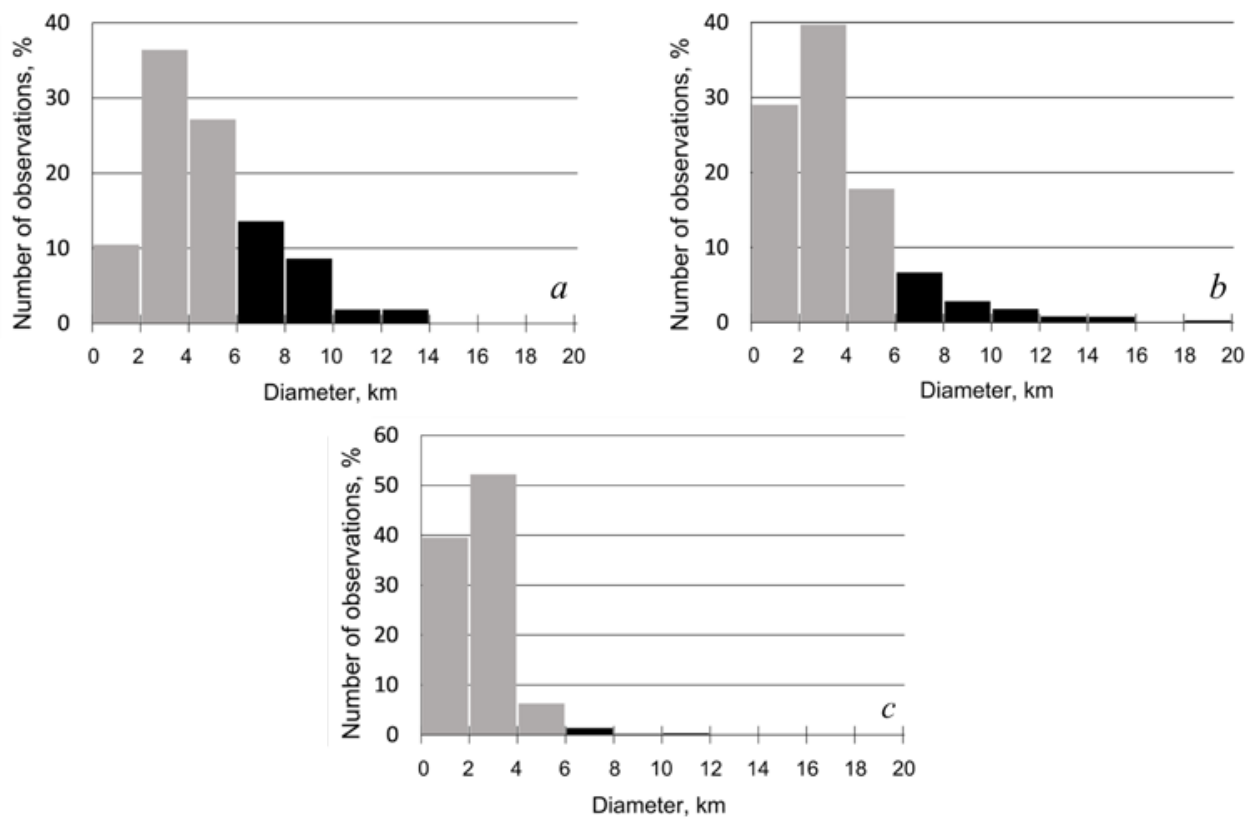

Fig. 4. Histograms of the distribution of diameters of the eddy structures in the waters of the White (a), Barents $(b)$ and Kara (c) Seas

Conclusion. Comparative analysis of the spatiotemporal variability of small eddies in the White, Barents and Kara Seas, registered on the basis of the analysis of satellite radar images during the ice-free period of the year, was carried out. Coordinates of the location of the eddy centers, their diameters and the type of rotation were determined. It allowed the future identification of the areas of quasiregular observation of the eddy structures, their seasonal variability estimation and discussion of the possible mechanisms (sources) of eddy generation in these areas.

Analysis of satellite measurements for the three Arctic seas resulted in the detection of 3591 surface manifestations of small eddies. The eddies were encountered practically throughout the entire water area of these seas. At that, the average number (the number of all registered eddies in relation to the sea area) was 1.4 and 1.8 eddy per $1.000 \mathrm{~km}^{2}$ in the Kara and White Sea, respectively. The maximum amount of eddies was recorded in the Barents Sea, but the average number was only 1.5 eddy per 1.000 $\mathrm{km}^{2}$. This is due to the compact location of the eddies in the several separate sea areas.

The areas of regular observation of eddy structures are the following:

- in the White Sea - the Dvina Gulf, areas to the north of the Solovetsky Islands and near the Tersky coast (up to 40 eddies per $1.000 \mathrm{~km}^{2}$ );

- in the Barents Sea - its southern part, areas to the west of Franz Josef Land, near the eastern coast of Western Spitsbergen, between Novaya Zemlya and Franz Josef Land, where the number of eddies reached 14 per $1.000 \mathrm{~km}^{2}$;

- in the Kara Sea - between Severny Island of Novaya Zemlya and the Yamal Peninsula, in the area of the Uyedineniya and Sverdrup (the Pyasino Gulf) Islands, where the number of eddies reached 11 per $1.000 \mathrm{~km}^{2}$. 
Maximum repeatability is observed in the eddies having dimensions close to the estimates of the first baroclinic deformation radius (an internal Rossby radius). Eddies with diameters less than $6 \mathrm{~km}$, referred to the sub-mesoscale ones, were encountered most often in the Kara Sea - approximately in $95 \%$ cases. In the White Sea, they were registered in about $80 \%$ cases, in the Barents Sea - in about $85 \%$ cases. In some rare cases the eddies with diameters up to $25 \mathrm{~km}$ were registered (particularly in the Barents Sea). The average diameter of the eddies varied from $2.4 \mathrm{~km}$ in the Kara Sea to $4.7 \mathrm{~km}$ in the White Sea.

The dynamics and instability of fronts of various origins, as well as topographic effects, seem to be the mechanisms of formation of eddy structures in the studied seas. The peak of the largest eddy activity was observed in July in the Barents and White Seas, and in August - in the Kara Sea. It also should be noted that in the Kara and White Seas a significant number of eddies are located near the frontal zones formed due to river runoff. This corresponds well to the climatic maximum of the river runoff observed in August for the Kara Sea and in July for the White Sea. The fact that the maximum number of eddies in all the seas was observed near the frontal zones and corresponded to the months of the greatest activity of hydrological fronts should motivate future studies of the regularities of the front variability and its relation to eddy dynamics in the Arctic Ocean.

Acknowledgements. The reported study was funded by RFBR research project No. 16-35-60072 mol_a_dk (data order and processing) and No. 15-05-04639 (data analysis and eddy structure registration), and also the State Order No. 0827-20140011 (software development for data analysis). Envisat ASAR data were obtained from the European Space Agency (ESA) through ESA Project C1F-29721.

\section{REFERENCES}

1. Thomas, L.N., Tandon, A. and Mahadevan, A., 2008. Submesoscale Processes and Dynamics. In: M.W. Hecht and H. Hasumi, eds. 2008. Ocean Modeling in an Eddying Regime. Washington, D.C.: American Geophysical Union, pp. 17-38. doi:10.1029/177GM04

2. Capet, X., McWilliams, J.C., Molemaker, M.J. and Shchepetkin, A.F., 2008. Mesoscale to Submesoscale Transition in the California Current System. Part I: Flow Structure, Eddy Flux, and Observational Tests. J. Phys. Oceanogr., [e-journal] 38(1), pp. 29-43. doi:10.1175/2007JPO3671.1

3. Zatsepin, A.G., Kremenetskiy, V.V., Ostrovskii, A.G., Baranov, V.I., Kondrashov, A.A., Korzh, A.O. and Soloviev D.M., 2011. Submesoscale Eddies at the Caucasus Black Sea Shelf and the Mechanisms of Their Generation. Oceanology, [e-journal] 51(4), pp. 554-567. doi:10.1134/S0001437011040205

4. Luk'yanov, P.V., 2013. Dinamika Kompaktnogo Vikhrya v Zone Pribrezhnogo Shel'fa [Dynamics of a Compact Eddy in the Coastal Shelf Zone. Morskoy Gidrofizicheskiy Zhurnal, (1), pp. 21-33 (in Russian).

5. Özgökmen, T.M., Poje, A.C., Fischer, P.F. and Haza, A.C., 2011. Large Eddy Simulations of Mixed Layer Instabilities and Sampling Strategies. Ocean Modelling, [e-journal] 39(3-4), pp. 311-331. doi:10.1016/j.ocemod.2011.05.006

6. Gurova, E. and Chubarenko, B., 2012. Remote-Sensing Observations of Coastal SubMesoscale Eddies in the South-Eastern Baltic. Oceanologia, [e-journal] 54(4), pp. 631-654. doi:10.5697/oc.54-4.631 
7. Kostianoy, A.G., Ginzburg, A.I., Sheremet, N.A., Lavrova, O.Yu. and Mityagina, M.I., 2010. Melkomasshtabnye Vikhri Chernogo Morya [The Black Sea Small-Scale Eddies Small-Scale Eddies in the Black Sea]. Sovremennye Problemy Distantsionnogo Zondirovaniya Zemli iz Kosmosa, [e-journal] 7(1), pp. 248-259. Available at: http://jr.rse.cosmos.ru/article.aspx?id=687\&lang=eng [Accessed 2 November 2016] (in Russian).

8. Karimova, S.S., 2012. Statisticheskiy Analiz Submezomasshtabnykh Vikhrey Baltiyskogo, Chernogo i Kaspiyskogo Morey po Dannym Sputnikovoy Radiolokatsii [Statistical Analysis of Sub-Mesoscale Eddies of the Baltic, Black and Caspian Seas Based on Satellite Radar Data]. Issledovanie Zemli iz Kosmosa, (3), pp. 31-47 (in Russian).

9. Rogachev, K., 2010. Submezomasshtabnye Strui na Kontinental'nom Shel'fe Zaliva Petra Velikogo (Yaponskoe More) [Submesoscale Streamers on the Continental Shelf of the Peter The Great Bay]. Sovremennye Problemy Distantsionnogo Zondirovaniya Zemli iz Kosmosa, [e-journal] 7(3), pp. 186-190. Available at: http://jr.rse.cosmos.ru/article.aspx?id=761\&lang=eng [Accessed 1 November 2016] (in Russian).

10. Dubina, V.A., Fayman, P.A. and Ponomarev, V.I., 2013. Vikhrevaya Struktura Techeniy v Zalive Petra Velikogo [Vortex Structure of Currents in Peter the Great Bay]. In: Izv. TINRO. Vladivostok. Vol. 173, pp. 247-258 (in Russian).

11. Kubryakov, A.A. and Stanichny, S.V., 2015. Dynamics of Batumi Anticyclone from the Satellite Measurements. Physical Oceanography, [e-journal] (2), pp. 57-68. doi:10.22449/1573160X-2015-2-59-68

12. Dulov, V.A., Yurovskaya, M.V. and Kozlov, I.E., 2015. Coastal Zone of Sevastopol on High Resolution Satellite Images. Physical Oceanography, [e-journal] (6), pp. 39-54. doi:10.22449/1573-160X-2015-6-39-54

13. Zimin, A.V., Atadzhanova, O.A., Romanenkov, D.A., Kozlov, I.E. and Chapron, B., 2016. Submezomasshtabnye Vikhri v Belom More po Dannym Sputnikovykh Radiolokatsionnykh Izmereniy [Sub-Mesoscale Eddies in the White Sea According to Satellite Radar Measurements]. Issledovanie Zemli iz Kosmosa, [e-journal] (1-2), pp. 129-135. doi:10.7868/S020596141506010X (in Russian).

14. Dobrovol'skiy, A.D. and Zalogin, B.S., 1982. Morya SSSR [The Seas of USSR]. Moscow: MGU Publ., 192 p. (in Russian).

15. Nurser, A.J.G. and Bacon, S., 2014. The Rossby Radius in the Arctic Ocean. Ocean Sci., [e-journal] 10(6), pp. 967-975. doi:10.5194/os-10-967-2014

16. Romanenkov, D.A., Zimin, A.V., Rodionov, A.A., Atadzhanova, O.A. and Kozlov I.E., 2016. Izmenchivost' Frontal'nykh Razdelov i Osobennosti Mezomasshtabnoy Dinamiki Vod Belogo Morya [Variability of Fronts and Features of Mesoscale Water Dynamics in the White Sea]. Fundamental'naya i Prikladnaya Gidrofizika, 9(1), pp. 59-72 (in Russian). 